\title{
Formation of pedagogical and psychological mechanisms of student self-government
}

\author{
${ }^{1}$ Researcher, Uzbekistan
}

\author{
I. M. Shoniyazova ${ }^{1}$
}

Email:shoniyazovai@@umail.uz.

\begin{abstract}
This article discusses the psychological mechanisms student self-government, as well as pedagogical mechanisms. Self-government is one of the most important aspects today. Job also focuses on student leadership skills.

Keywords: student, self-confidence, self-esteem, adequacy, liberalism, authoritarianism, skill, knowledge, skill, qualification.
\end{abstract}

\section{INTRODUCTION}

Ensuring the quality of education in our country, educational institutions strengthening the material and technical base and methodological support, the work of teachers and improving living conditions, humanizing education and the democratization reforms have affected the prestige and prestige of the pedagogical profession in our society increase, the widespread introduction of person-centered learning models in the educational process creates an opportunity. Self-awareness, a sense of self-control to be able to make full and effective use of educational services, scientific and to be able to become a professional in order to achieve a thorough mastery of professional knowledge lays the foundation for.

As the President of our country Sh. M. Mirziyoyev noted, "We are education and upbringing the operation of all links of the system in accordance with modern requirements

\section{MAIN PART}

We see improvement as our number one priority. " education is about reforming society and making it more open and new to the outside world is a key factor in transforming it into a society focused on technology and knowledge.

Modernization of the education system, reform of its most important area, today it is necessary to take into account only the needs of the state and civil society, the expansion of social responsibilities in educational institutions, the requirements of the individual, his prioritize the creation of conditions for the most complete determination of sustainability and it is important to develop each student's potential and self-management is important.

In the organization of the teacher-student relationship in the present period, in general to the radical changes taking place in the country and the modernization of education and in response to the education system resulting from integration processes.

We can see the issues related to cooperation. The student's self-improvement of pedagogical and psychological mechanisms of preparation for management. One of the issues of the education system is the development of interaction between teachers is happening. The relationship of the subjects of the educational process in educational institutions scientific-theoretical-practical preparation for humanization and democratization required.

By a number of scholars on student self-governance recognized. (A.V. Batarshev, S.L. Bratchenko, A. Grebtsov, V.A. Kan-Kalik, N.V. Kuzmina, L.A. Petrovskaya, E.I. Rogov, R.X. Shakurov, P.M. Jacobson). These scientists developing a system of student self-management in the learning process in his works. The problem is highlighted in the organization of student self-government interpersonal relationships as an essential condition for successful activity issues of interdependence between culture and management culture are sufficient organization of student self-government system and pedagogical and psychological relations of teachers and students in development a number of theories, even if there is a certain theoretical and practical experience of the study The issues are not sufficiently developed, including the teacher-coach what is its role in this process, what are its features in different educational institutions, basic conditions for improvement in the context of modernization of education and directions are not disclosed.

Student self-governance in higher education is education in the process their ability to think independently is the highest manifestation and in social life means to find its place. Self-expression is the foundation of self-management upbringing in civil society, social interaction throughout his life developing skills, fulfilling responsibilities and organizing them strengthen the ability to submit to collective discipline and at the 
same time own psychological protection of their rights, group and personal interests allows communication with the public. Student self-management meaning students' "authority", not leadership relationships, or to the personal experience of democratic relations and its implementation It does not depend on the availability of forms, selfmanagement of students democratic in an educational environment, not a specific "management activity" ensuring the dynamics of relationships, students' self-reliance in civil society additional and independent activities that provide opportunities for self-realization is a way of organizing. Participation in self-governing bodies, other like any activity, the student defends himself as a person, a person make their own interests and abilities one of the team teams at the same time allows you to understand as part of.

Cooperation of pedagogical staff in higher education institutions, cooperation with the family the following solution in the organization of student self-government in the practice of doing allowed to identify unresolved issues.

Students in modern pedagogical and psychological theory and practice public education despite the urgency of self-governance issues educational work in institutions is still formal, stereotypical, pedagogical and psychological impact on students, not active subjects of social life to choose, to act independently and responsibly, to take an independent position, to be free ideas about the active person who is able to manifest are the same as before student self-management so that it does not remain at the level of declarations including the extensive use of educational potential in collaboration with teachers there is a need for other training practices. In addition, teachers and the modern stage of developing student interaction complex and contradictory, mutual rudeness, intolerance in relationships, misunderstandings, pedagogical and psychological conflicts.

President of the Republic of Uzbekistan Islam Karimov signed a decree on February 7, 2017, on the Strategy of Actions for the Further Development of the Republic " No. 4947, dated October 8, 2019 "On the system of higher education of the Republic of Uzbekistan 2030 Decree No. PF-5847 "On approval of the concept of development up to April 20, 2017 "Measures for further development of the higher education system no. PQ2909 of June 5, 2018 "On education in higher education institutions improving the quality and comprehensiveness of their implementation in the country additional measures to ensure active participation in reforms Resolution No. PQ-3775 of Pedagogical Psychology of Preparing Students for Self-Management scientific research has been conducted by a number of scientists. In Uzbekistan, on self-government HI Ibragimov, E. Goziyev, A. Khalikov, MG Davletshin, K. Zaripov, I. Karimov, N. Komilov, N. M. Maxmudov, S. Nishonova, D. Narzikulova, M.Ochilova, M. Pirmuhamedova, N.Muslimov, K.Qodirov, A.Avazboyev, A.Ismadiyarov, E. Migranov, Sh. Pozilova conducted research. The views expressed by many of our scholars above are that young people are selfsufficient preparation for management, self-management functions, students' own in society through the urgency of finding a place and self-governance "High spirituality in the formation of personality. It turns out that S. Nishanova is one of the few studies We can also see the results of research conducted by the use of a number of techniques in psychological self-management plays an important role. In the method of self-observation, the student observes his own mental phenomena examines, in which all cognitive processes play a role. Of this method through a series of student self-management of shortcomings and successes students can achieve success through external and internal self-governance they strengthen the willpower. Every person's will is one but it focuses on changing and managing events in the external world, and it's as well as to manage their own personal subjective state and processes can direct.

- The desire of students to show a number of features in self-government, desire, purpose and most importantly inner strength of will. -Any goal in student self-government and its implementation the choice of paths sometimes results in a number of processes that have different attractions.

This process reveals the nature of the involvement and internal struggle of the matinees in this case, students have a struggle of motives in self-government.

Every person, including students, has an internal motivational struggle. Competence specific to direct pedagogy and psychology in a number of studies its peculiarities have been studied. Such research includes AK Markova we can include research conducted as a result of the research, the educator's self-confidence, as a person there was talk of self-esteem and self-control.

- Important pedagogical and psychological qualities in the professional activity of teachers that is, to create compassion, love for children, and the need for self-improvement - self-development and self-development in the acquisition of pedagogical skills important. Self-development tasks include self-analysis and self-awareness is determined by the assessment itself.

Every student or teacher first and foremost works on their own knowledge and skills conduct ongoing research and development to improve their skills

It is also necessary to be self-sufficient and creative in everything approach, development of hard work, pedagogical and creative cooperation to achieve. To give up one's negative habits through self-management, one's own self-improvement is also the embodiment of the qualities embodied in it is a necessary task of pedagogue and psychologist. 


\section{CONCLUSION}

Pedagogue and psychologist increase the efficiency of the work process by increasing its business activity mastering the knowledge that is updated daily, from the means of advanced technology. It is important to be aware of this and its incarnation certainly delights the heart. Self-assessment in the teaching process - self-assessment of a person through self-analysis. Self-assessment it should help the individual to discover his or her abilities on his or her own.

\section{REFERENCES}

1. The Decree of the President of the Republic of Uzbekistan dated February 7, 2017 "Uzbekistan On the Strategy of Actions for the Further Development of the Republic" Resolution No. 4947.

2. F.I.Khaydarov, N.T Khalilova. General psychology. (Textbook) Tashkent -2009.

3. Pedagogical theory / textbook for higher education. Mual .: M.X.Toxtaxodjayeva va. Others Prof. Under the general editorship of M.Kh. Tokhtakhodjayeva. - T .: «Iqtisod-moiya», 2010.

4. Pedagogy: 1000 answers to 1000 questions / Methodical manual.

5. Inoyatov UI, Muslimov NA, Usmonbaeva M., Inogamova D. - T .: Nizami Tashkent State Pedagogical University, 2012.

6. Turdiyeva M. Formation of pedagogical thinking in students of higher educational institutions. llation. - T.: TDPU named after Nizami, 2008.

7. Usmonbaeva, A. Turaev, Fundamentals of Creative Pedagogy. Educational-methodical complex. -. TDPU, 2016. 